East African Medical Journal Vol. 79 No. 5 May 2002

ATTITUDES OF MEDICAL STUDENTS TO INDUCED ABORTION

G. A. B. Buga, MBChB, MMed, PhD University of Transkei. Private Bag X01, Unitra, Umtata, South Africa

\title{
ATTITUDES OF MEDICAL STUDENTS TO INDUCED ABORTION
}

\author{
G. A. B. BUGA
}

\begin{abstract}
Background: Unsafe abortion causes $13 \%$ of maternal deaths worldwide. Safe abortion can only be offered under conditions where legislation has been passed for legal termination of unwanted pregnancy. Where such legislation exists, accessibility of safe abortion depends on the attitudes of doctors and other healthcare workers to induced abortion. Medical students as future doctors may have attitudes to abortion that will affect the provision of safe abortion. Little is known about the attitudes of South African medical students to abortion.

Objectives: To assess sexual practices and attitudes of medical students to induced abortion and to determine some of the factors that may influence these attitudes.

Design: A cross-sectional analytic study involving the self-administration of an anonymous questionnaire.

Setting: The questionnaire was administered to medical students at a small, but growing, medical school situated in rural South Africa.

Main Outcome measures: Demographic data, sexual practices and attitudes to induced abortion.

Results: Two hundred and forty seven out of $300(82.3 \%)$ medical students responded. Their mean age was $21.81 \pm 3.36$ (SD)years, and $78.8 \%$ were Christians, $17.1 \%$ Hindus and $2.6 \%$ Muslims. Although $95 \%$ of the respondents were single, $68.6 \%$ were already sexually experienced, and their mean age at coitarche was 17.24 \pm 3.14 (SD) years. Although overall $61.2 \%$ of the respondents felt abortion is murder either at conception or later, the majority $(87.2 \%)$ would perform or refer a woman for abortion under certain circumstances. These circumstances, in descending order of frequency, include: threat to mother's life $(74.1 \%)$, in case of rape $(62.3 \%)$, the baby is severely malformed $(59.5 \%)$, threat to mother's mental health $(53.8 \%)$ and parental incompetence $(21.0 \%)$. Only $12.5 \%$ of respondents would perform or refer for abortion on demand, $12.8 \%$ would neither perform nor refer for abortion under any circumstances. Religious affiliation and service attendance significantly influenced some of these attitudes and beliefs.

Conclusion: Although many of the medical students personally felt abortion is murder, the majority are likely to perform or refer patients for abortion under certain circumstances; only about a tenth are likely to perform or refer patients for abortion on demand.
\end{abstract}

\section{INTRODUCTION}

Unwanted pregnancy is a common problem worldwide. It is estimated that about 50 million pregnancies are terminated each year around the world(1,2). About 20 million of these are unsafe abortions which contribute considerably to maternal morbidity and mortality, especially in developing countries $(3,4)$. Safe abortion can only be offered under conditions where appropriate legislation has been passed for legal termination of unwanted pregnancy. Such legislation or lack of it often generates a lot of discussion and meets with either stiff resistance or approval from various sectors of society, including medical personnel(5-13).

Legal abortion was introduced in South Africa in February 1997, following on the promulgation of the
Choice on Termination of Pregnancy Act of 1996, making it one of the few countries in Africa with such legislation. Although the full impact of the legislation providing for safe abortion on maternal death rates in South Africa remains to be fully assessed, abortion-related deaths accounted for only $5.7 \%$ of maternal deaths in 1998(14), compared to $13 \%$ of maternal deaths due to unsafe abortion worldwide $(2,3)$.

Accessibility and when patients present for legal abortion play important roles in abortion-related deaths. The number of doctors and other health care personnel willing to perform legal abortion is affected by general social attitudes. Women's success in obtaining safe abortion is dependent on their doctors' attitudes to legal abortion. If the doctors are opposed to abortion on demand, this will affect access to safe abortion for women who seek it, especially where the options are limited as in rural areas(15). 
The continued availability of legal abortion depends on the willingness of future doctors to provide the service(16). Medical students are the future doctors. Their attitudes to abortion will affect patients' access to abortion(17-19). It has been reported that most medical students come to medical school with relatively fixed opinions about abortion, and ethics course and years of medical school socialisation do not change these opinions much $(17,18)$.

Little is known about the attitudes of medical students in South Africa to abortion and other reproductive health issues. The main aim of this study was to assess the attitudes of medical students to induced abortion and some of the factors which influence these attitudes.

\section{MATERIALS AND METHODS}

This was part of a larger cross-sectional analytic study using a comprehensive anonymous questionnaire administered to medical students from the first to the sixth year in a small but growing medical school in South Africa. The students were required to fill in demographic data such as age, sex, the year of study and religion. Anonymous information was also sought on such issues as sexual practices, religious service attendance, basis of personal ethical beliefs and morals, medical socialisation and attitudes to induced abortion. The questionnaire consisted mainly of forced-choice questions. The respondents put the completed questionnaires in envelopes and sealed them before collection by research assistants. Strict confidentiality was maintained.

The data were entered and analysed using EPINFO 6 statistical package. Frequency tables were generated for all the variables, and comparisons were made between females and males and between the years of study using the $\chi^{2}$ test. Associations were sought between variables where appropriate.

\section{RESULTS}

Demographic data: Two hundred and forty seven out of a total of 300 medical students in 1999 returned their completed questionnaires, with a response rate of $82.3 \%$.

The demographic characteristics of respondents are shown in Table 1. The majority of respondents were female and single. The age of the respondents ranged from $15-36$ years with a mean of $21.81 \pm 3.36(\mathrm{SD})$. Over threequarters of the respondents belonged to the various denominations; the rest were Hindus and Muslims. Just over $50 \%$ of the respondents attended religious services regularly; the rest attended irregularly or hardly at all. Significantly more female respondents attended religious service regularly than male respondents $\left(\chi^{2}=6.1 ; \mathrm{df}=2\right.$; $p=0.045$ ). About two-thirds of the respondents had the Bible and the Ten Commandments as the basis for their personal ethical beliefs and morals, followed by Hinduism, family or secular values, and Islam.

Sexual behaviour and practices: Table 1 also shows the sexual behaviour of the respondents. A little over twothirds of the respondents were sexually experienced, the rest had never had sexual intercourse. Religious affiliation was significantly associated with sexual experience, with
Table 1

Demographic characteristics of respondents and sexual behaviour

No. of
respondents $\%$

A. Demographic

Sex of respondents $(n=246)$

Female

$136 \quad 55$

Male

$110 \quad 44.7$

Marital status $(n=236)$

Single

Married

$225 \quad 95.3$

Separated/divorced

95.3
4.2
0.4

gious affiliation $(n=245)$

Christian

10

Hindu

Muslim

Other

Religious attendance $(n=247)$

Regular attendance

Irregular attendance

Rare attendance

Basis of ethical beliefs/morals $(n=244)$

Bible and Ten commandments

Hinduism

Family or secular values

Islam

1

$193 \quad 78.8$

$42 \quad 17$.

2.4

1.6

53.4

$\begin{array}{ll}132 & 53.4 \\ 106 & 42.9\end{array}$

$9 \quad 3.6$

$166 \quad 68.0$

$40 \quad 16.4$

$33 \quad 13.5$

5

2.0

B. Sexual behaviour

Sexual experience $(n=245)$

Ever had sex

Never had sex

$168 \quad 68.6$

$77 \quad 31.4$

Most recent episode of sexual intercourse $(\mathrm{n}=161)$

Past week

Past month

More than 2 months back

43.5

21.1

35.4

Use of contraceptives during most recent coitus $(n=165)$

Used

Not used any

Type of contraceptive used $(n=149)$

Condoms

Oral contraceptive pill

Nuristerate

9.4

15.4

IUCD

Christians being more sexually experienced than Hindus $\left(\chi^{2}=25 ; \mathrm{df}=4 ; \mathrm{p}=0.000\right)$. Of the sexually experienced respondents, the mean age when they first had sexual intercourse was $17.24 \pm 3.14$ (SD) years. Majority of sexually experienced respondents $(64.6 \%)$ had the most recent coitus within a month prior to filling the questionnaires. Majority of them used some form of contraceptive during their most recent coitus, with condoms being most commonly used. A quarter of the sexually experienced respondents had been pregnant or responsible for a pregnancy before. Of these pregnancies, $4.5 \%$ were terminated by induced abortion. Nearly a third $(31.5 \%)$ of the respondents had ever masturbated; significantly more male than female respondents had ever masturbated $\left(\chi^{2}=8.04 ; \mathrm{df}=3 ; \mathrm{p}=0.045\right)$. Over half $(56.3 \%)$ of the respondents had never masturbated and $12.2 \%$ did not know what masturbation is. Of those who 
had ever masturbated, $36.1 \%$ masturbated regularly; $27.9 \%$ masturbated irregularly and $35 \%$ rarely masturbated.

\section{Table 2}

Attitudes of respondents to induced abortion and circumstances under which they would or perform or refer for abortion

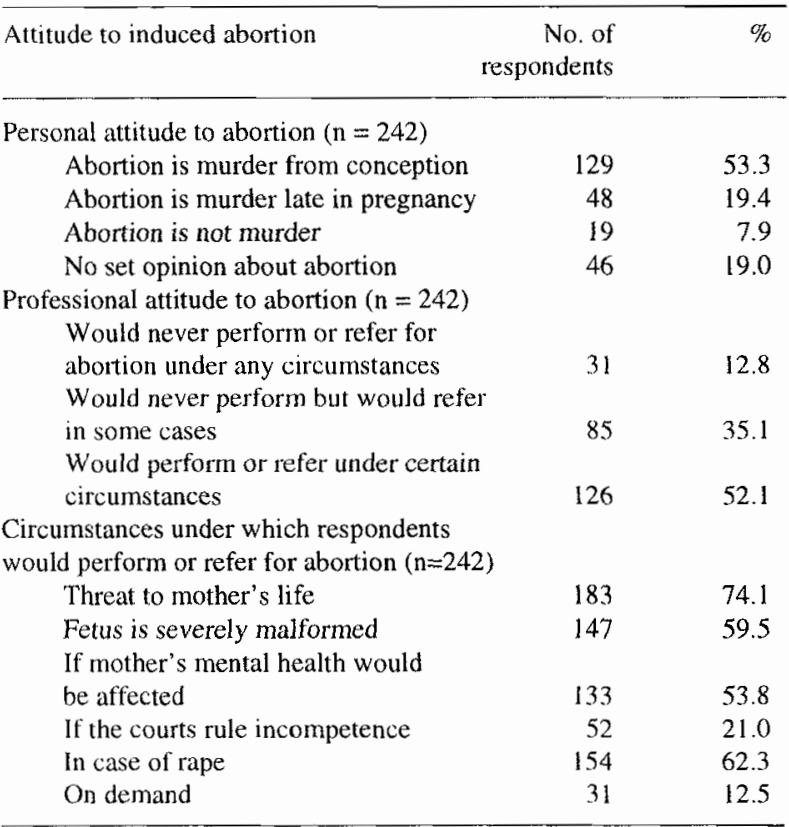

Personal attitude to induced abortion: The attitudes of respondents to induced abortion are shown in Table 2. Over half of the respondents felt that induced abortion is murder right from conception. Less than a tenth of the respondents felt that abortion is not murder. When the responses were analysed for factors that might influence personal attitudes to abortion, it was found that there was no significant association with the gender of the respondents $\left(\chi^{2}=5.71 ; \mathrm{df}=4 ; \mathrm{p}=0.221\right)$. Sexual experience had no association with personal attitude of respondents to induced abortion $\left(\chi^{2}=2.77 ; \mathrm{df}=4 ; \mathrm{p}=0.597\right)$. The year of study in medical school (medical socialisation) also did not have any significant association with the personal attitudes to abortion $\left(\chi^{2}=23.8 ; \mathrm{df}=20 ; \mathrm{p}=0.248\right)$. Religion, however, had a significant association with the personal attitudes to abortion. Significantly more Christians than Hindus respondents felt abortion is murder from conception $\left(\chi^{2}=\right.$ $32.51 ; \mathrm{df}=16 ; \mathrm{p}=0.0008$ ). The basis of personal ethics and morals had a significant association with personal attitudes to abortion. About 59\% of respondents held the Bible or the Ten commandments as the basis of their personal ethics, compared with $30.7 \%$ of respondents with Hinduism as the basis for personal ethics, felt that abortion was murder $\left(\chi^{2}=28.35 ; \mathrm{df}=12 ; \mathrm{p}=0.004\right)$. Prior experience of induced abortion or being a partner to a person who had induced abortion had no significant association with personal attitude to abortion $\left(\chi^{2}=3.67\right.$; $\mathrm{df}=4 ; \mathrm{p}=0.451)$
Professionalattitude to inducedabortion: A minority of the respondents felt that they would never perform abortion under any circumstances (Table 2). Over half of the respondents would perform or refer patients for abortion under certain circumstances. Only $12.5 \%$ of respondents would perform or refer for abortion on demand. When analysis was based on gender, no differences were observed between male and female respondents in their professional attitudes to abortion. The year of study, however, had a significant influence on the professional attitudes to abortion, with a higher proportion of first year students $(22.1 \%)$, compared to other years, feeling they would never perform or refer anyone for abortion under any circumstances $\left(\chi^{2}=24.45 ; \mathrm{df}=15\right.$;

$\mathrm{p}=0.05$ ). Religious affiliation had no significant influence on professional attitudes to abortion, although a higher proportion of respondents who attended religious services regularly $(17.5 \%)$ than those who attended irregularly (7.8\%) would never perform or refer for abortion under any circumstances $\left(\chi^{2}=16.93 ; \mathrm{df}=6 ; p=0.009\right)$. Neither sexual experience, nor the basis of personal ethics had any significant influence on professional attitudes to abortion. However, personal attitude to abortion significantly influenced professional attitude to abortion $\left(\chi^{2}=55.85 ; \mathrm{df}\right.$ $=12 ; \mathrm{p}=0.000)$. The choice of future professional specialisation had no significant influence on professional attitudes to abortion ( $\left.\chi^{2}=38.8 ; \mathrm{df}=51 ; \mathrm{p}=0.903\right)$.

Conditions under which respondents would perform or refer for abortion: The circumstances under which respondents would refer or perform abortion and the frequency distribution are shown in Table 2. Only $12.5 \%$ of the respondents would perform or refer for abortion on demand. Nearly three-quarters of the respondents would perform or refer a patient for abortion if her life was threatened by continuing the pregnancy. This included seven respondents who stated that they would never refer any patient or perform an abortion under any circumstances Only one respondent would not be moved by threats to the patient's life by the pregnancy. Threat to maternal health had a strongly significant effect on professional attitude to abortion $\left(\chi^{2}=21.87 ; \mathrm{df}=3 ; \mathrm{p}=0.000\right)$. The rest would perform an abortion or refer a patient for one when the fetus is severely malformed, the patient's mental health is threatened by the pregnancy and in case of rape. A fifth of the respondents would perform or refer for abortion if the courts rule the mother to be incompetent.

Choice of specialty: In an attempt to assess if the attitudes to induced abortion might influence the respondents' choice of future specialisation, they were asked to indicate these fields. The choices of future specialisation were as follows: surgical specialities (21.9\%); paediatrics (15.3\%); medical specialities $(7.4 \%)$; obstetrics and gynaecology $(2.6 \%)$; undecided $(26.6 \%)$. The rest wanted to specialise in various other disciplines or become general practitioners. The choice of future specialisation had no significant association with professional attitudes to abortion $\left(\chi^{2}=38.37 ; \mathrm{df}=51 ; \mathrm{p}=\right.$ 0.903 ). 


\section{DISCUSSION}

This study was carried out in a small but growing medical school with predominantly black students and a significant minority of students of Asian origin. The findings may therefore not be representative of the attitudes of all medical students in South Africa, the majority of whom are still white. However, to our knowledge, this is the first report of its kind from South Africa.

The personal attitude to abortion of the majority of medical students in this survey was that abortion is murder either from conception $(53.3 \%)$ or later in pregnancy $(19.4 \%)$. This attitude was significantly influenced by religious affiliation, regularity of religious service attendance and the basis of personal ethics, but not by gender, sexual experience previous induced abortion or year of study This is in contrast to a report from the USA where medical students with previous sexual experience, female gender, or previous experience of abortion were more likely to have more liberal attitude to abortion(17. 19). In general, medical students of Hindu religious affiliation were more tolerant towards induced abortion than Christian medical students. Interestingly, from a professional point of view, only $12.8 \%$ of the medical students in this survey would never perform an abortion under any circumstances, although about $70 \%$ of the students personally feit that abortion is murder. A significantly higher proportion of first year medical students felt that they would never perform an abortion under any circumstances than more senior students. The majority would perform an abortion or refer a patient for an abortion if her life was in danger, the fetus was abnormal, in cases of rape or if the mental health of the mother would be affected by the pregnancy. This is similar to the professional attitudes of medical students from Johns Hopkins University(17). Only $12.5 \%$ would perform or refer for abortion on demand.

It is evident from this study that personal and professional views about abortion are not the same. Even though the majority personally felt that abortion is murder, yet they still saw abortion as justifiable under certain circumstances. The resolution of such a moral dilemma as this requires individuals to come to terms with conflicts between competing values. Medical training and socialisation appears to change the professional views of medical students as they become more senior. This is suggested by the fact that senior students had a more positive attitude to performing an abortion or referring a patient for abortion than first year students, even though the majority of them personally believed abortion is murder. Others have also reported that the attitudes of medical students to abortion become more liberal during their time at medical schools $(17,18)$.

This study shows that the medical students were evenly divided into one group that would not perform abortion under any circumstances, and another group that would perform abortion on demand. It is unclear what the future impact of this finding will be in South Africa on the provision of safe abortion to women who require it. However, what is encouraging is that the majority of students have a positive attitude to performing or referring patients for abortion under certain circumstances, including risk of pregnancy on the health of the patient, in spite of their own personal beliefs about abortion. They might just be persuaded to offer abortion services when they become more aware of the effects of unsafe abortion on maternal morbidity and mortality (1-4).

\section{REFERENCES}

1. Van Look P.F.A. and von Hertzen H. Induced abortion: a global view. In: Grimes D.A., Van Look P.F.A. (eds). Baird D. T. Modern Methods of Inducing Abortion. Oxford, Blackwell Science, 1995:1 24.

2. A Joint WHO/UNFPA/UNICEF/World Bank Statement Reduction of maternal mortality. Geneva, World Health Organization, 1999.

3. World Health Organization. Unsafe abortion: Global and Regional Estimates of Incidence and Mortality due to Unsafe Abortion with Listing of Available Country Data. 3rd Edition. Document WHO/ RHT/MSM/97. 16.

4. World Health Organization. Unsafe abortion - a major public health problem. Safe Motherhood 2000: 28:4-8.

5. Benatar S.R., Abels C., Abratt R., Anthony J., Benatar D. and Brooks D. et al. Abortion - some practical and ethical considerations. S Afr Med J 1994; 84:469-472.

6. Smith J. Abortion - a debate. S Afr Med J 1995; 85:137-139.

7. Hardy W., Gilpin T., Stead M., van Andel P. and Somasumeran A Abortion legislation (letter). S Afr Med J 1996; 86:1433.

8. Thomas C. Doctors for life abortion on demand survey (letter) $S$ Afr Med J 1996; 1561-1562.

9. Van Der Merwe T.L., Moll A.P. and Eksteen F.J. Abortion on demand (letter). S Afr Med $J 1997 ;$ 87:74-75.

10. Yankauer A. Abortion: the divisive issue. Am J Public Health 1985: 75:714-715.

11. Tribe L.H. Abortion. The Class of Absolutes. New York: WW Norton. 1990.

12. Callahan D. How technology is reframing the abortion debate. Hastings Center Rep. 1986; 16:33-42.

13. Nathanson C.A. Perspectives on abortion. London: Scarecrow Press. 1985.

14. National Committee on Confidential Enquiries into Maternal Deaths. A review of maternal deaths in South Africa. SAfr Med J 2000; 90:367-373

15. Rosenblatt R.A., Mattis R. and Hart L.G. Abortion in rural Idaho physicians' attitudes and practices. Am J Public Health 1995; 85: $1423-1425$

16. Rosenblatt R.A., Robinson K.B., Larson E.H. and Dobie S.A. Medical students' attitudes towards abortion and other reproductive health services. Fam Med 1999; 31:195-199.

17. Dans P.E. Medical students and abortion: reconciling personal beliefs and professional roles at one medical school. Acad Med 1992; 67:207-211.

18. Leiblum S.R., Rosen R.C., Platt M., Cross R.J. and Black C. Sexual attitudes and behavior of a cross-sectional sample of United States medical students: effects of gender, age, and year of study, J Sex Educ Therapy 1993; 19:235-245.

19. Klamen D.I., Grossman L.S. and Kopacz D.R. Attitudes to abortion among second year medical students. Med Teacher 1996; 18:345346. 